ESTUDIOS 



\section{1. \\ Derecho privado}



Revista de Derecho

de la Pontificia Universidad Católica de Valparaíso

XXX (Valparaíso, Chile, $1^{\text {er }}$ Semestre de 2008)

[pp. 35 - 59]

\title{
CELEBRACIÓN DE MATRIMONIOS RELIGIOSOS CIVILMENTE ILEGALES EN CHILE
}

[Celebration of Religious Marriages Which are Illegal from the Civil Standpoint in Chile]

\author{
Cristian Cajas Silva* \\ Universidad de Chile
}

ResUmen

Después de 120 años sin variaciones significativas, la nueva Ley de matrimonio civil reformuló en 2004 el párrafo del Código Penal dedicado a la celebración de matrimonios ilegales, derogando algunos artículos y modificando otros. Una de las orientaciones perceptibles, es la renovada consideración del matrimonio religioso. En este trabajo se analizan dogmáticamente los delitos indicados, destacando la categoría de los matrimonios religiosos civilmente ilegales y, en especial, la situación del matrimonio canónico. Para efectos de orden y sistematización, el trabajo se desarrolla en cuatro partes: la primera se refiere a los matrimonios ilegales; la segunda, al bien jurídico protegido por los delitos contemplados en el párrafo de la celebración de matrimonios ilegales; la tercera, al análisis particular de los delitos; y la cuarta, al proceso penal.

Palabras clave: Matrimonio civil - Matrimonio religioso - Matrimonios ilegales - Matrimonios prohibidos - Bigamia - Ministro de culto.

\section{Abstract}

After 120 years without any essential changes, in 2004 the new Civil Marriage Act re-enacted the paragraph of the Criminal Code dedicated to the celebration of illegal marriages, derogating some articles and modifying others. One of the perceivable orientations is the renewed consideration of the religious marriage. In this work we will analyse, from a dogmatic standpoint, the aforementioned offences, highlighting, from the civil standpoint, the category of the illegal religious marriages, especially, the situation of the canonic marriage. For order and systematization purposes, this is divided into four parts: The first part refers to illegal marriages; the second, to the legal good protected by the offences contemplated in the paragraph of celebration of illegal marriages; the third part is a particular analysis of the offences; and the fourth part refers to the criminal process.

KeYwords: Civil marriage - Religious marriage - Illegal marriages - Prohibited marriages - Bigamy - Minister of religious affairs.

* Abogado, Universidad de Chile. Correo electrónico: cristiancajas@yahoo.es 


\section{LOS MATRIMONIOS ILEGALES}

La familia es el cuerpo intermedio más importante de la sociedad. Su rol se expresa en cuatro aspectos básicos: reproducción, socialización, protección y comunidad. El orden legal definido por el Estado conforma la familia legítima y su base es el matrimonio (artículo 1 inciso $1^{\circ}$ LMC.). Por esta razón, las normas que regulan el matrimonio son de orden público y tradicionalmente se han establecido penas para afianzar su cumplimiento.

A fines del siglo IX, cuando en Occidente la Iglesia católica comienza a ejercer jurisdicción exclusiva sobre el matrimonio, en el derecho canónico "las sanciones impuestas eran generalmente la separación de los cónyuges,

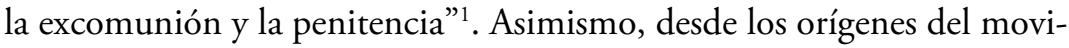
miento codificador, en el siglo XIX, los códigos penales han contemplado delitos referentes al matrimonio ${ }^{2}$.

La tipificación de delitos en materia matrimonial se manifiesta en dos aspectos: la celebración de matrimonios ilegales, que castiga los matrimonios celebrados con vicios de forma o de fondo; y la precedencia del matrimonio civil al religioso, que obedece a la necesidad del Estado de asegurar la aplicación del matrimonio civil, frente a la raigambre social del matrimonio canónico, durante su proceso de aparición y consolidación.

\section{El matrimonio canónico y religioso en el derecho penal chileno.}

El Código Penal chileno fue publicado en 1874, en circunstancias que al régimen de confesionalidad de Estado aún le restaba medio siglo de vigencia y que el sistema matrimonial era de constitución dualista del tipo subsidiario. El matrimonio canónico era jurídica y socialmente la regla general. La ley civil lo establecía con carácter obligatorio y, como es natural en una sociedad con profunda influencia religiosa, la abrumadora mayoría de la población sólo consideraba legítimo realizar su enlace conyugal ante la Iglesia. En subsidio, las personas que no profesaban la religión católica tenían la posibilidad de optar por una ceremonia civil, que igualmente se realizaba ante el párroco y cuyas normas sustantivas correspondían al derecho canónico.

El párrafo del Código Penal dedicado a la celebración de matrimonios

${ }^{1}$ García y García, Antonio, Historia del Derecho canónico (Salamanca, 1967), I, p. 407.

${ }^{2}$ Pacheco, Joaquín Francisco, El Código Penal, concordado y comentado (4a edición, Madrid, 1870), III, p. 216: "Todas las legislaciones del mundo han puesto al matrimonio bajo su garantía. No podía menos de ser asi; porque el matrimonio es la base de la familia, y la familia es la sociedad. De aqui son las penas contra lo que le pervierte". 
ilegales tiene importantes antecedentes religiosos y en nuestro país ha sufrido una interesante evolución. Originalmente obedecía a un fundamento canónico, pues suponía la jurisdicción de la Iglesia católica sobre el matrimonio. Por ejemplo, el artículo 383 se refería a los impedimentos dispensables y no dispensables, y a la revalidación del matrimonio, que son instituciones del derecho canónico. En 1884, la Ley de matrimonio civil reservó al Estado la jurisdicción legislativa y judicial en materia matrimonial, pero el citado párrafo permaneció casi inalterado. El hecho fue subsanado parcialmente en la Ley sobre registro civil de 1930. Su artículo 43 contemplaba una figura penal, bastante confusa, pero pretendía asegurar la aplicación del matrimonio civil imponiendo su precedencia al matrimonio religioso. Aunque el delito no tuvo aplicación práctica significó una evolución cualitativa, porque incorporó al derecho penal chileno la categoría de los matrimonios religiosos, en circunstancias que antes sólo se consideraba al matrimonio canónico. La Ley de matrimonio civil de 2004 (LMC.) derogó dicho artículo e introdujo diversas modificaciones en el Código Penal, todo lo cual se debe a una renovada (y errada) consideración del matrimonio religioso.

\section{Ineficacia civil del matrimonio religioso.}

Durante la tramitación del proyecto de la nueva Ley de matrimonio civil, se presentó en el Senado una indicación para otorgar efectos civiles a los matrimonios religiosos y al matrimonio indígena. Su principal finalidad era contrarrestar el ámbito de aplicación del divorcio vincular, a través de la afirmación de los matrimonios religiosos, ya que en su especie más tradicional entre nosotros se observa la indisolubilidad del vínculo conyugal. Sin embargo el tema no es inocuo y su discusión enfrentó resistencias, lo que se refleja en las fuertes limitaciones impuestas al reconocimiento y la equivocada formulación de su valor en el artículo 20 LMC. De un lado, está el breve plazo de ocho días para proceder a la inscripción del acta de matrimonio religioso, su calidad de plazo fatal y la exigencia de que los cónyuges comparezcan personalmente, sin que pueda conferirse mandato al efecto; y de otro, la errada comprensión del acto ratificatorio, que a pesar de su denominación legal, no retrotrae sus efectos al acto ratificado y desde todo punto de vista constituye una celebración civil del matrimonio.

El resultado fue una simple declaración programática. Los efectos civiles de los matrimonios religiosos celebrados ante entidades religiosas de derecho público son accesorios a la celebración efectiva del matrimonio civil, por tanto, virtuales y carentes de sentido; y además son exclusivamente formales, debido a que se refieren únicamente al rito religioso. En consecuencia, nuestro sistema matrimonial continúa siendo de matrimonio civil 
obligatorio, con la única variante de que los contrayentes pueden optar porque el inicio sea bajo la forma religiosa de su denominación ${ }^{3}$.

\section{EL BIEN JURÍDICO PROTEGIDO POR LOS DELITOS TIPIFICADOS EN EL PÁRRAFO SOBRE CELEBRACIÓN DE MATRIMONIOS ILEGALES}

Existen diversas posiciones sobre el bien jurídico protegido. En el Código Penal español de 1848, que es el antecedente directo del nuestro, el bien jurídico es el estado civil. Así se desprende de su sistematización. El título $12^{\circ}$ del libro II se denomina De los delitos contra el estado civil de las personas y tiene dos capítulos: Suposición de partos y usurpación del estado civily La celebración de matrimonios ilegales. Acerca del título duodécimo, el comentarista español Pacheco señala que "el estado civil comprende todo lo que respecta á la condición social de las personas. El nombre del individuo, sus derechos y obligaciones de familia, su posición en el estado y en la sociedad: he aqui lo que abarca verdaderamente la materia a que se contrae el presente título"s. Sin embargo, él advierte que dicho bien jurídico no es completamente ajustado para todos los delitos que incluye el título y, apuntando a los delitos contemplados en el capítulo segundo, expresa: "Si quizá alguno de los artículos que vamos a ver, no entra perfectamente en el límite de esta esfera [el estado civil], por lo menos no podrá negarse que tenga con ella analogía y numerosos puntos de contacto. No puede exigirse más rigor en una obra de la naturaleza del Código"s.

Para el profesor Mario Garrido Montt, en cambio, el bien jurídico "no es el matrimonio en cuanto estado civil, sino la estructura de ese vínculo, concebido por razones de interés público, en forma monogámica; de suerte que lo amparado de modo inmediato es el matrimonio mismo, lo que adquiere relevancia en el caso de la bigamia"6. Aunque esta posición es más precisa, a mi juicio, su concepción es muy limitada, pues se construye esencialmente desde el delito de bigamia.

Por su parte, el profesor Alfredo Etcheberry analiza el criterio definido por el legislador en la sistematización de nuestro Código Penal. El título $7^{\circ}$ del libro II se denomina Crimenes y simples delitos contra el orden de las

${ }^{3}$ Ver Salinas Araneda, Carlos, Matrimonio civil y matrimonio religioso, en VV. AA., El nuevo derecho chileno del matrimonio (Santiago, Editorial jurídica de Chile, 2006), p. 76.

${ }^{4}$ Pacheco, Joaquín Francisco, cit. (n. 2), III, p. 209.

${ }^{5}$ Ibíd.

${ }^{6}$ Garrido Montt, Mario, Derecho penal (2a edición, Santiago, Editorial Jurídica de Chile, 2005), III, p. 255.

${ }^{7}$ Etcheberry Orthusteguy, Alfredo, Derecho penal (3a edición, Santiago, Editorial Jurídica de Chile, 2004), IV, pp. 9-10. 
familias y contra la moralidad pública ${ }^{8}$. Por lo cual distingue dos categorías de delitos: los que atentan contra el orden de las familias y los referidos a la moralidad pública. En su opinión, el orden de las familias ha sido considerado en un doble aspecto: por una, la constitución jurídica de la familia y las relaciones familiares que nacen de ella; y por otra, el recto uso de la función sexual. Al primer aspecto se refieren los delitos contra el estado civil de las personas y la celebración de matrimonios ilegales. Por tanto, según Etcheberry, el bien jurídico protegido por los delitos sobre celebración de matrimonios ilegales, es la constitución jurídica de la familia.

En mi opinión, esta última posición es la más ajustada a la estructura de nuestro Código Penal y a la naturaleza de los delitos en cuestión. La constitución jurídica de la familia es una noción más amplia que el matrimonio. Permite enfatizar que el matrimonio no es un valor en sí mismo, es un medio, que alcanza su plenitud en tanto fuente y base de la familia legítima. Así se desprende de una interpretación sistemática, principalmente del artículo 1 incisos $2^{\circ}$ y $5^{\circ}$ de la Constitución Politica de la República y del artículo 1 inciso $1^{\circ}$ de la Ley de matrimonio civil.

A pesar de lo precedente, es necesario señalar que doctrinariamente se discute la utilidad y legitimidad de la intervención penal en esta materia, principalmente en base al carácter subsidiario del derecho penal. Entre nosotros, así lo expresan los profesores Garrido Montt ${ }^{9}$ y Rodríguez Collao ${ }^{10}$.

${ }^{8} \mathrm{El}$ título $7^{\mathrm{o}}$ incluye los siguientes párrafos: Aborto, Abandono de niños y personas desvalidas, Crimenes y simples delitos contra el estado civil de las personas, Del rapto (derogado), De la violación, Del estupro y otros delitos sexuales, Disposiciones comunes a los dos párrafos anteriores, De los ultrajes públicos a las buenas costumbres, Del incesto y Celebración de matrimonios ilegales.

${ }^{9}$ Garrido Montt, Mario, cit. (n. 6), III, p. 255: "Los distintos tipos que se sancionan [en el párrafo celebración de matrimonios ilegales] se refieren a matrimonios celebrados con vicios de forma o de fondo. Aparte de lo dudoso que pueda ser elevar a la categoría de delito materias como las señaladas, algunas son de tan poca trascendencia que bien podrían haber sido consideradas faltas, hoy es aconsejable su eliminación".

${ }^{10}$ Rodríguez Collao, Luis, Protección penal del estatuto jurídico del matrimonio, en Guzmán Brito, Alejandro (ed.), Colección de estudios de derecho civil en homenaje a la profesora Inés Pardo de Carvallo (Ediciones Universitarias de Valparaíso, Pontificia Universidad Católica de Valparaíso, Valparaíso, 2008), p. 184: "La existencia de un grupo de delitos destinado a la protección del matrimonio es un asunto que merece serios cuestionamientos desde una perspectiva político-criminal. Las críticas apuntan fundamentalmente a la ineficacia del Derecho penal como instrumento válido para el logro de aquel objetivo; a los riesgos que la intervención penal en este campo representa para el respeto a la capacidad de autodeterminación del individuo y la libertad de conciencia, y, por último, a la necesidad de reconocer al Derecho 


\section{LOS DELITOS DE CELEBRACIÓN DE MATRIMONIOS ILEGALES}

A partir de la nueva Ley de matrimonio civil, los delitos que integran el párrafo del Código Penal destinado a la celebración de matrimonios ilegales, pueden dividirse en dos categorías, según sean aplicables al matrimonio civil o al matrimonio religioso. Debido al aparente reconocimiento civil de los matrimonios religiosos, no es evidente cuáles delitos pertenecen a cada categoría. Incluso, en algunos casos, se podría llegar a pensar que son aplicables a ambos matrimonios indistintamente.

Seguidamente se analizarán todos los delitos del párrafo indicado, comenzando por los delitos que son aplicables al matrimonio religioso, y luego los que no lo son. Los primeros serán denominados celebración de matrimonios religiosos civilmente ilegales. Se dice que son "civilmente ilegales" y no simplemente "ilegales", porque los matrimonios religiosos no son típicos en sí mismos, sino, sólo en cuanto pueden llegar a ser el inicio de un matrimonio civil. Los restantes, se agruparán bajo el nombre de celebración de matrimonios civiles ilegales.

\section{CELEBRACIÓN DE MATRIMONIOS RELIGIOSOS CIVILMENTE ILEGALES}

Forman parte de este grupo los siguientes delitos: el ministro de culto que autoriza un matrimonio prohibido (CP. artículo 388 inciso $1^{\circ}$ ), la falsedad del acta de matrimonio religioso (artículo 388 inciso $2^{\circ}$ CP.) y la obstaculización de la inscripción del matrimonio religioso (artículo 389 CP.). El primer delito, figura añadido al delito de autorización o inscripción de matrimonio prohibido, que sólo es aplicable al oficial civil, razón por la cual serán tratados en forma conjunta.

En los delitos sobre celebración de matrimonios religiosos civilmente ilegales, hay dos conceptos normativos que integran el tipo penal y requieren de una valoración jurídica para fijar su alcance: matrimonio religioso y ministro de culto: i) Matrimonio religioso: son aquéllos que pueden llegar a ser el inicio de un matrimonio civil. Para tal efecto, el artículo 20 LMC. establece los siguientes requisitos: rito religioso, ante entidades religiosas que tengan personalidad jurídica de derecho público, cumplimiento de los requisitos de validez del matrimonio civil ${ }^{11}$ y otorgamiento del acta del matrimonio religioso. ii) Ministro de culto: su determinación queda entregada a la reglamentación de las respectivas entidades religiosas. En el caso de la Iglesia católica, las personas calificadas para celebrar validamente

penal un carácter subsidiario frente a otros mecanismos de control social".

${ }^{11}$ Ley No 19.947, artículos 5, 6, 7 y 8. 
un matrimonio canónico son el Ordinario del lugar (obispo o vicarios) y el párroco, el sacerdote o el diácono delegado por uno de aquéllos, y los laicos autorizados (Código de Derecho Canónico, cánones $1108 \$ 1$ y 1112 \$1).

\section{Autorización o inscripción de matrimonio probibido (artículo 388} inciso $1^{\circ}$ CP.).

En la indicación 227-344, de 13 de septiembre de 2001, el Presidente de la República propuso derogar los artículos 386 a 389 CP. Respecto del artículo 388, la Comisión de constitución, legislación y justicia del Senado no compartió la idea. Aunque sí accedió a complementarlo a la luz de la inscripción de los matrimonios religiosos. Así, el artículo séptimo No 3 de la Ley No 19.947 de 2004, sustituyó el artículo 388 CP. Actualmente, su inciso $1^{\circ}$ expresa lo siguiente: "El oficial civil que autorice o inscriba un matrimonio prohibido por la ley o en que no se hayan cumplido las formalidades que ella exige para su celebración o inscripción, sufrirá las penas de relegación menor en su grado medio y multa de seis a diez unidades tributarias mensuales. Igual multa se aplicará al ministro de culto que autorice un matrimonio prohibido por la ley".

En relación al texto anterior, éste se estructura en base a dos tipos penales con las siguientes innovaciones: i) en el primero se limitó el sujeto activo, que antes era el "funcionario eclesiástico o civil" y actualmente sólo puede ser "el oficial civil"; ii) se extendió la acción típica, que antes consistía en la "autorización de un matrimonio prohibido por la ley o en que no se hayan cumplido las formalidades que ella exige para su celebración" y actualmente comprende, en ambos casos, la inscripción del mismo; iii) se estableció un tipo penal especial para castigar al ministro de culto que autorice un matrimonio prohibido por la ley, disponiendo la multa como sanción.

a) El tipo penal objetivo. El primero consiste en la autorización o inscripción de un matrimonio prohibido por la ley; o bien, con infracción de las formalidades que ésta dispone para su celebración o inscripción. El delito es de acción, de mera actividad e instantáneo. Pero lo más relevante de esta figura, es que se trata de un delito especial. El tipo penal exige para su perfeccionamiento que la conducta sea ejecutada por un sujeto específico, el oficial del registro civil. Asimismo, es un delito de propia mano, porque debido a la naturaleza del tipo penal, la acción típica solo puede ser cometida por una actividad corporal del propio sujeto activo.

La acción contempla dos conductas distintas: autorizar un matrimonio civil, que significa celebrarlo; e inscribir un matrimonio, que puede ser de celebración civil (artículo 19 inciso 1o LMC.) o religiosa (artículo 20 inciso $2^{\circ}$ LMC.). A su vez, la tipicidad de las acciones indicadas, puede 
deberse a que el matrimonio está prohibido por la ley o se incumplen las formalidades legales, sea para la celebración o inscripción. Por tanto, es factible una multiplicidad de infracciones, que van desde una formalidad hasta un impedimento dirimente absoluto o relativo. En cualquier caso, se trata de los mandatos contenidos en la Ley de matrimonio civil (capítulo II: De la celebración del matrimonio) y en la Ley sobre registro civil (títulos 10: Disposiciones generales y $3^{\circ}$ : De los matrimonios).

El segundo tipo penal especial, es para castigar "al ministro de culto que autorice un matrimonio prohibido por la ley". Es semejante al tipo anterior y seguramente por ello se describen en forma conjunta. Pero en este caso se trata del inicio religioso del matrimonio civil. Dicho inicio se efectúa a través de un matrimonio religioso. Mas, sólo es religioso en cuanto al rito, el fondo debe ajustarse a la ley civil, precisamente porque el matrimonio es civil y no religioso.

¿Cómo se determina que un matrimonio religioso está prohibido por la ley civil? Hay que remitirse al inciso $1^{\circ}$ del artículo 20 LMC. Éste señala que los matrimonios religiosos producirán los mismos efectos que el matrimonio civil, "siempre que cumplan con los requisitos contemplados en la ley, en especial lo prescrito en este Capitulo [...]". El capítulo indicado es el segundo, que se rubrica: De la celebración del matrimonio y tiene cuatro párrafos: De los requisitos de validez del matrimonio, De las diligencias previas a la celebración del matrimonio, "De la celebración del matrimonio y De los matrimonios celebrados ante entidades religiosas de derecho público. El párrafo $4^{\circ}$ sólo contiene el artículo citado. Los párrafos segundo y tercero, únicamente se aplican al matrimonio civil iniciado directamente en el Registro Civil. El párrafo $1^{\circ}$, en cambio, se aplica al matrimonio civil cualquiera sea su forma de inicio. Luego, el matrimonio religioso, para efectos de ser el inicio del matrimonio civil, debe observar sus disposiciones. Asimismo, el artículo 40 bis No 10 de la Ley sobre registro civil, establece que el acta de matrimonio religioso debe expresar "El hecho de haberse cumplido las exigencias establecidas en la ley para la validez del matrimonio civil". Por tanto, el ministro de culto autoriza un matrimonio "prohibido por la ley" cuando no hay consentimiento libre y espontáneo de los contrayentes (artículo 8 LMC.) y cuando se infringen los impedimentos dirimentes, sean absolutos (artículo 5 LMC.) o relativos (artículos 6 y 7 LMC.).

Además, ambos tipos penales se distinguen por la extensión de la acción típica y las penas aplicables.

El ministro de culto no es sancionado por no haber "cumplido las formalidades que [la ley] exige para su celebración o inscripción”. Esto se debe a que el rito o celebración matrimonial, es el único aspecto que la ley civil entrega a la norma de la respectiva entidad religiosa. En ese ámbito el ministro 
de culto tiene autonomía, de hecho la ley reconoce como manifestación concreta de la libertad religiosa, la facultad de "practicar en público o en privado, individual o colectivamente, actos de oración o de culto; conmemorar sus festividades; celebrar sus ritos" ${ }^{\prime 2}$. También es lógico que al ministro de culto no se le haga extensiva la responsabilidad por la inscripción del matrimonio, porque éste no interviene en dicha instancia.

De otro lado, el oficial civil es castigado con pena corporal de relegación menor en su grado medio (541 días a 3 años) y multa de 6 a 10 UTM (\$198.114 a \$330.190 en agosto de 2007). El ministro de culto, en cambio, solamente con multa. La mayor severidad con aquél, es explicable por su carácter de funcionario público y la pena de multa, en ambos casos, se justifica por el propósito de inhibir la posibilidad de una retribución indebida.

b) El tipo penal subjetivo. La determinación del tipo penal subjetivo es más controvertida. Es seguro que el delito no se tipifica si el sujeto activo es negligente. En nuestro ordenamiento jurídico penal, la culpa es punible sólo cuando se encuentra expresamente tipificada (artículos 4 y 10 No 13 CP.).

También se excluye la culpabilidad del oficial civil cuando actúa engañado, violentado o intimidado. El engaño impide la conciencia de antijuridicidad; la violencia y la intimidación, hacen imposible exigir una conducta conforme a derecho. Asimismo, coincido con el profesor Garrido Montt, que en las hipótesis aludidas el tipo penal se desplaza al descrito en el artículo 384 CP. Si el engaño, la violencia o la intimidación afectan al ministro de culto, también se excluye su culpabilidad, pero la responsabilidad penal del autor de los hechos tendría que ajustarse a los delitos generales, como las lesiones (artículos 395 y ss. CP.) o las amenazas (artículos 296 y ss. CP.).

La dificultad se presenta con el dolo. Mientras Garrido Montt ${ }^{13}$ lo circunscribe a dolo directo, los profesores Etcheberry ${ }^{14}$ y Rodríguez Collao ${ }^{15}$ sostienen la procedencia del dolo eventual.

El dolo directo debe cumplir dos requisitos: la conciencia de ilicitud y la voluntad de llevar a efecto el delito. Según la posición mayoritaria, el dolo eventual se distingue del directo en el segundo factor, es decir, el sujeto también tiene conciencia del probable resultado ilícito que encierra su conducta, pero no actúa con esa intención, sino en forma despreocupada

\footnotetext{
${ }^{12}$ Artículo 6 letra b, Ley No 19.638: Sobre constitución jurídica de las iglesias y organizaciones religiosas (DO. 14 de octubre de 1999).

${ }^{13}$ Garrido Montt, Mario, cit. (n. 6), III, p. 267.

${ }^{14}$ Etcheberry Orthusteguy, Alfredo, cit. (n. 7), IV, p. 36.

${ }^{15}$ Rodríguez Collao, Luis, cit. (n. 10).
} 
o indiferente. Si en la misma situación, el sujeto actúa confiando que el resultado ilícito no se producirá, es culpa consciente y no dolo eventual. En la situación concreta del oficial del registro civil y del ministro de culto, la autorización del matrimonio se fundará en los conocimientos propios de su función y en los antecedentes suministrados por los cónyuges que sean necesarios para efectuar la celebración. Por tanto, actuarán confiando que el matrimonio no es de aquellos prohibidos por la ley civil o de lo contrario negarán la autorización. Luego, si yerran, podrá haber culpa o, más aún, culpa consciente. Pero no hay dolo eventual y la conducta no será típica.

c) El iter criminis. Atendido el tiempo necesario para su consumación, la autorización o inscripción de matrimonio prohibido es de naturaleza instantánea, porque se consuma al momento de inscribir o celebrar matrimonio. Mas, la celebración y la inscripción, también son actos complejos, por tanto es procedente la frustración y la tentativa (artículo 7 CP.). La frustración opera cuando el autor pone todo de su parte para autorizar o inscribir el matrimonio, pero el acto no se completa por causas ajenas a su voluntad. La tentativa existe cuando se ejecutan los actos iniciales de la celebración o inscripción, pero faltan otros necesarios para su terminación.

d) La responsabilidad penal del ministro de culto. La consagración de un tipo penal especial para castigar al ministro de culto que autoriza un matrimonio prohibido por la ley civil, es el mejor ejemplo de la confusión que guía nuestro actual modelo de reconocimiento civil de los matrimonios religiosos. Si dicho reconocimiento hubiera sido efectivo, se justificaría la introducción del tipo penal, porque se habría atribuido a los ministros de culto el ejercicio de una potestad pública y estarían en posición de cometer irregularidades. Sin embargo, ya es sabido que el artículo 20 LMC. no alteró la sustancia de nuestro sistema monista de matrimonio civil único. La actuación de los ministros de culto no tiene efectos jurídicos autónomos en el sistema matrimonial chileno, por tanto la intervención penal resulta completamente injustificada.

i) Autoría y participación: a pesar de lo que señalaré más adelante sobre la procedencia de este delito, considero necesario detenerme en este punto. En base al concepto legal de autor, el profesor Carlos Salinas Araneda, nos alerta sobre la extensión que puede alcanzar la aplicación de este delito respecto de los posibles responsables.

El artículo 15 CP. dispone: "Se consideran autores: 10 Los que toman parte en la ejecución del hecho, sea de una manera inmediata y directa, sea impidiendo o procurando impedir que se evite. $2^{\circ}$ Los que fuerzan o inducen directamente a otro a ejecutarlo. $3^{\circ}$ Los que, concertados para su ejecución, 
facilitan los medios con que se lleva a efecto el hecho o lo presencian sin tomar parte inmediata en él'.

No sólo es autor de un delito el ejecutor de la acción típica, también lo es el denominado autor cooperador o coautor, contemplado en el No 3 del artículo 15 CP. En opinión del distinguido profesor, "en esta última disposición queda incluido el Ordinario del lugar -esto es obispo o vicarios- que autorice la celebración del matrimonio canónico que no puede ser matrimonio civil, porque está facilitando los medios para que aquél se pueda realizar; $y$, además, los testigos, porque concertados para su ejecución, lo presencian sin tomar parte inmediata en él; precisamente, su función es presenciar el matrimonio para dar testimonio de su celebración. Y hasta podría pensarse en los mismos invitados"16.

No comparto la autorizada opinión. Previamente se expuso que este delito es especial y de propia mano. De modo que únicamente puede ser autor el sujeto que tiene la calidad de ministro de culto. Esto descarta la posibilidad de que un testigo o un invitado sea coautor del delito.

Para aclarar aún más el asunto y tratar la situación de los otros tipos de participación criminal que podrían presentarse (principalmente de los cómplices), hay que revisar los principios reguladores de la participación. Entre ellos, es pertinente el principio de la comunicabilidad, o más bien la teoría, porque se busca determinar si las calidades personales y los elementos subjetivos del tipo se extienden a los coautores o demás participes que no los cumplen; y en la afirmativa, precisar cuándo y cómo se verifica dicha extensión.

Los tratadistas no están de acuerdo, para algunos existe comunicabilidad y para otros rige la incomunicabilidad absoluta. La incertidumbre se origina porque, a diferencia de las circunstancias modificatorias de la responsabilidad penal (artículo $64 \mathrm{CP}$.), aquí no hay norma expresa que resuelva el tema. Así, de un lado, Garrido Montt sostiene la primacía de la fase subjetiva del tipo penal, "cada sujeto que interviene en el delito responde de su propio dolo"17; y Etcheberry plantea la comunicabilidad con una salvedad, "para determinar si se trata de una circunstancia de esta especie, es preciso eliminarla mentalmente y verificar si el hecho, sin ella, sigue siendo delictivo o no. En este último caso, se trata de una circunstancia que integra el tipo y se comunica" ${ }^{18}$. En la vereda opuesta, Cury se inclina por la incomunicabilidad absoluta de los elementos subjetivos y calidades que integran el tipo delictivo ${ }^{19}$.

\footnotetext{
${ }^{16}$ Salinas Araneda, Carlos, cit. (n. 3), pp. 83-84.

${ }^{17}$ Garrido Montt, Mario, cit. (n. 6), II, p. 331.

${ }^{18}$ Etcheberry Orthusteguy, Alfredo, cit. (n. 7), II, p. 84.

${ }^{19}$ Cury Urzúa, Enrique, Derecho penal. Parte general (Santiago, Editorial Jurí-
} 
Adhiero a la opinión de Cury. Principalmente en base a la exigencia de tipicidad, que arranca del principio de legalidad en la formulación de los delitos. La ley penal debe describir expresamente los hechos y circunstancias que los constituyen (Constitución Política, artículo 19 No 3 inciso 8). En consecuencia, en este delito, la actuación de los coautores y cómplices que no poseen la calidad de ministro de culto no es típica.

La duda permanece respecto de los otros participantes que tengan la calidad de ministro de fe. Aquí hay que distinguir. En el caso de los sacerdotes o diáconos que intervienen como co-celebrantes del matrimonio religioso, se configura la coautoría contemplada en el artículo 15 No 3 CP. Debido a que existe un acuerdo previo de voluntades y la intervención de cada uno de los concertados en la ejecución del hecho ${ }^{20}$. La situación es diferente para el obispo o vicario que otorga dispensa a un matrimonio canónico que no puede ser matrimonio civil (Código de Derecho Canónico, canon $1071 \$ 1$ No 2). En este caso se responde a título de complicidad (artículo 16 CP.). No es un coautor, porque no hay un concierto previo ${ }^{21}$, sólo una autorización. Tampoco hay intervención en la ejecución del hecho ("facilitación de los medios"), pues el ordinario del lugar no interviene en la celebración del matrimonio favorecido con la dispensa.

ii) Ausencia de lesividad e inconstitucionalidad: "el legislador no es libre para sancionar cualquier conducta; puede hacerlo únicamente cuando tiene motivos que legitiman el ejercicio de esa facultad, y ello sucede cuando se dirige a la protección de bienes jurídicos valiosos. Solo pueden ser sancionadas penalmente las conductas que lesionan o ponen en peligro intereses jurídicos socialmente valiosos" 22 . Esto debido a que "el delito es

dica de Chile, 1992), II, p. 229: “De acuerdo con el principio de comunicabilidad -que, en rigor, debiera más bien ser rotulado principio de incomunicabilidad-, a los concurrentes no se comunican aquellos elementos subjetivos o calidades personales que sólo se dan en uno o algunos de ellos y que forman parte del tipo delictivo, siendo, por ende, determinantes, ya para la incriminación de la conducta, ya para su calificación a un título específico. Quien concurre con la cónyuge en el acto de dar muerte al marido no es coautor de parricidio, sino de homicidio; quien concurre con el funcionario público a sustraer los fondos públicos o particulares que éste tiene a su cargo, no es coautor de malversación de caudales públicos, sino de hurto, apropiación indebida o estafa, según cuáles sean las circunstancias concretas en que se ejecuta el acto; quien, sin haberlo premeditado, concurre con el que sí lo ha hecho a dar muerte a otro, no es coautor de homicidio calificado, sino de homicidio simple; quien coopera o induce a un miembro de los tribunales de justicia para que a sabiendas falle contra ley expresa y vigente en causa criminal o civil, ha de quedar impune".

${ }^{20}$ Garrido Montt, Mario, cit. (n. 6), II, p. 312.

${ }^{21}$ Ibíd.

${ }^{22}$ Ibíd, I, p. 43. 
ante todo lesión del bien jurídico y no violación del deber, particularmente para un derecho penal que atribuya importancia primordial a la víctima y a las consecuencias del hecho punible"23.

Pues bien, contrariamente a lo que parece entender nuestro legislador, lo cierto es que si un ministro de culto autoriza un matrimonio prohibido, no lesiona ni coloca en riesgo ningún bien jurídico, sea éste la constitución jurídica de la familia, el matrimonio mismo o cualquier otro. En primer lugar, a ojos del Estado el matrimonio religioso sólo es un acto privado que no goza por sí mismo de ningún efecto civil. Más aún, para los contrayentes, es una opción que corresponde al ejercicio legítimo de un derecho: la libertad religiosa (Ley No 19.638, artículo 6). En segundo lugar, el ministro de culto no tiene ningún vínculo con el Estado que lo obligue a cautelar sus intereses en el ámbito matrimonial. Y, en cambio, el legislador encargó al oficial del registro civil la función de verificar que la celebración religiosa cumplió los requisitos legales. Incluso le otorgó facultades para negar la inscripción (artículo 20 inciso $3^{\circ}$ LMC.). Por tanto, la circunstancia de que el matrimonio religioso pueda ser el inicio de un matrimonio civil, escapa a la determinación del ministro de culto.

La autorización de un matrimonio prohibido por la ley civil es un delito de peligro abstracto. De una parte, su consumación se satisface únicamente con la creación de un riesgo de lesión para el bien jurídico que pretende amparar; y de otra, no se precisa la comprobación del riesgo, es decir, si efectivamente la conducta estuvo en la posibilidad de lesionar dicho bien jurídico. Esto constituye una verdadera presunción de responsabilidad penal que no admite prueba en contrario. Es una presunción de derecho prohibida por el artículo 19 № 3 inciso $6^{\circ}$ de la Constitución, en lo referido al ministro de culto, es completamente inconstitucional.

iii) Alternativa canónica: lo señalado anteriormente corresponde al fuero civil, pero el ordenamiento jurídico de la Iglesia católica contempla instrumentos idóneos para impedir que sus ministros de culto sufran el rigor de normas como el artículo $388 \mathrm{CP}$. Así, el Código de Derecho Canónico dispone de la licencia del Ordinario del lugar (canon $1071 \$ 1$ No 2) y del matrimonio secreto (cánones 1130-1133).

El canon $1071 \$ 1$ del Código de Derecho Canónico contempla siete casos en que es necesaria la autorización del Ordinario del lugar (obispo o vicario), en forma previa, para la celebración del matrimonio. Son casos en que el matrimonio canónico puede conducir a situaciones irregulares

${ }^{23}$ Politoff, Sergio - Matus, Jean Pierre - Ramírez, María Cecilia, Lecciones de derecho penal chileno. Parte general ( $2^{\text {a }}$ edición, Santiago, Editorial Jurídica de Chile, 2003), I, p. 68. 
y por ello se requiere la venia de la autoridad eclesiástica. El $\mathrm{N}^{\circ} 2$, del $\$$ 1, del canon 1071, se refiere "al matrimonio que no puede ser reconocido o celebrado según la ley civil”. Sería el caso de las personas que ya están casadas civilmente, pues su matrimonio canónico con una persona distinta de su cónyuge civil no podría ser reconocido por la ley civil, porque existe un impedimento dirimente: el vínculo matrimonial civil precedente no disuelto. Sin embargo según, el derecho de la Iglesia son personas solteras.

La celebración del matrimonio en secreto es una modalidad de la forma ordinaria, caracterizada por constituir una limitación al principio de publicidad. Debido a una causa grave y urgente, la celebración se realiza con la obligación para los contrayentes, testigos y ministro asistente, de guardar secreto sobre su existencia y sin inscripción en el registro de la parroquia respectiva.

En virtud de estas instituciones, el obispo o vicario podrá conceder o denegar la licencia, para celebrar un matrimonio canónico que no puede ser matrimonio civil; y luego, en caso de optar por la afirmativa, podrá autorizar la celebración del referido matrimonio en secreto.

iv) Proyecto de ley: debido a las deficiencias de este tipo penal, el proyecto de ley que pretende perfeccionar el reconocimiento civil del matrimonio religioso ${ }^{24}$, también contempla modificar esta materia, porque estima que "el delito sólo se configura cuando el ministro de culto actúa con dolo y con el propósito de lograr el reconocimiento civil de un matrimonio que sabe ilegal". Se propone sustituir el artículo $388 \mathrm{CP}$. por el siguiente: "Igual multa se aplicará al ministro de culto que, a sabiendas y con el propósito de obtener el reconocimiento civil, autorice o asista un matrimonio prohibido por la ley".

La enmienda es una solución acertada. Otorga precisión al tipo penal en el ámbito subjetivo, pues limita la culpabilidad del sujeto activo a la existencia de dolo directo. Este criterio es resultado de una adecuada identificación de la conducta no deseada (el desvalor). Por ejemplo, la Iglesia católica en cumplimiento de su mandato evangelizador, en más de alguna oportunidad podrá enfrentarse a la necesidad de autorizar canónicamente un matrimonio prohibido por la ley civil. Sin embargo, la ilicitud está en pretender el reconocimiento civil de aquel matrimonio, que es una cuestión diferente y no pertenece a su afán. En consecuencia, un ministro católico difícilmente autorizará un matrimonio prohibido por la ley civil "con el propósito de obtener el reconocimiento civil".

Asimismo, desde una perspectiva político criminal, se justifica la exis-

${ }^{24}$ Cámara de Diputados, Boletín 3732-18, 30 de noviembre de 2004: “Modifica Ley de Matrimonio Civil para perfeccionar el reconocimiento civil de los matrimonios celebrados ante entidades religiosas". 
tencia del delito. El proyecto de ley es más amplio y propone múltiples modificaciones, que posibilitarían a los matrimonios celebrados ante entidades religiosas de derecho público, tener los mismos efectos que un matrimonio civil. Así, la intervención penal en este ámbito adquiere sentido, porque el ministro de culto ejercería una potestad pública que efectivamente podría lesionar la constitución jurídica de la familia.

\section{Falsedad del acta de matrimonio religioso (artículo 388 inciso $2^{\circ}$ CP.).}

El artículo séptimo No 3 de la Ley No 19.947, de 2004, incluyó un inciso $2^{\circ}$ al artículo 388, que dispone lo siguiente: "El ministro de culto que, con perjuicio de tercero, cometiere falsedad en el acta o en el certificado de matrimonio religioso destinados a producir efectos civiles, sufrirá las penas de presidio menor en cualquiera de sus grados".

a) El tipo penal. El delito es de acción, material e instantáneo. También se caracteriza por ser especial y de propia mano. El tipo sólo puede ser realizado por el ministro de culto. El sujeto pasivo, en cambio, puede ser cualquier persona. Principalmente alguno de los contrayentes.

La acción típica es cometer falsedad en el acta o en el certificado de matrimonio religioso destinados a producir efectos civiles. Es un tipo de falsedad ideológico, que consiste en consignar datos simulados en los documentos indicados. El resultado de la acción típica es el perjuicio de tercero. Ambos eventos deben estar vinculados por una relación causal.

El tipo penal sujetivo sólo puede ser dolo directo. La acción de falsificar exige plena conciencia y voluntad del autor.

En este caso la conducta es sancionada con mayor severidad por el legislador, porque se equiparó al delito de falsificación de instrumento privado (artículo 197 CP.). La pena es presidio menor en cualquiera de sus grados y supera la establecida para castigar al oficial civil que autoriza o inscribe un matrimonio prohibido por la ley, que es relegación menor en su grado medio y multa de seis a diez unidades tributarias mensuales (ver escala del artículo 59 CP.). Es otra de las incoherencias de nuestro sistema de reconocimiento civil de los matrimonios religiosos: en materia penal, las penas no son proporcionadas a la lesividad de la conducta.

b) El perjuicio de tercero. El tipo penal exige que la acción típica cause una consecuencia, que es el perjuicio a un tercero. No se especifica el tipo de perjuicio, sin embargo éste será principalmente jurídico o patrimonial. Sobre el particular, se debe considerar que la ley penal debe interpretarse siempre en forma restrictiva ${ }^{25}$. De lo contrario se violentaría

\footnotetext{
${ }^{25}$ Etcheberry Orthusteguy, Alfredo, cit. (n. 7), I, p. 103.
} 
su naturaleza subsidiaria y de derecho estricto. Probablemente un buen criterio sería adoptar el alcance jurídico del concepto perjuicio ${ }^{26}$.

La exigencia de que se perjudique a un tercero, hace de este delito, aquello que la doctrina denomina delito imposible o tentativa inidónea absoluta, esto "es cuando el sujeto que actúa cree que concurre un elemento del tipo penal que en realidad no existe, sea porque el medio empleado es totalmente inadecuado o porque no hay objeto que agredir" ${ }^{27}$. Son ejemplos habituales: el sujeto que hiere a un muerto creyéndolo dormido o el que administra una sustancia inofensiva creyéndola venenosa. La consecuencia práctica del delito imposible, es que la conducta ejecutada en dicho caso no es punible.

Ya se ha explicado que los matrimonios religiosos carecen de efectos civiles en forma autónoma. De hecho el legislador fijó el inicio de los efectos civiles en la ratificación ante el oficial civil, justamente para evitar perjuicios a terceros ${ }^{28}$. De modo que no se advierte cómo la falsedad en el acta o el certificado del matrimonio religioso podría provocarlos. Ciertamente, el ministro de culto podrá incurrir en dicha conducta, pero la posibilidad de que ésta cause perjuicios a un tercero no existe, porque el medio empleado es inadecuado y, por lo mismo, la comisión de este delito es totalmente imposible. Esto aún sin considerar las restricciones legales para proceder a la inscripción del acta: la necesidad de que los contrayentes asistan personalmente a ratificar su consentimiento, el breve plazo de ocho días y el control de legalidad efectuado por el oficial civil, en el cual éste se encuentra facultado incluso para denegarla.

c) El iter criminis. Atendidas las condiciones necesarias para su consumación, la falsificación del acta o certificado del matrimonio religioso, es un delito material o de resultado, que se perfecciona cuando la acción causa perjuicios a un tercero. Por tanto, es procedente la tentativa y la frustración.

d) Instrucción del fiscal nacional. En el oficio No 504, de octubre

${ }^{26}$ Real Academia Española, Diccionario de la lengua española (21 a edición, Editorial Espasa, Madrid, 2000), II, p. 1578: "Ganancia lícita que deja de obtenerse, o deméritos o gastos que se ocasionan por acto u omisión de otro, y que este debe indemnizar, a más del dańo o detrimento material causado por modo directo".

${ }^{27}$ Garrido Montt, Mario, cit. (n. 6), II, p. 292.

${ }^{28}$ Biblioteca del Congreso Nacional, Historia de la ley No 19.947: establece nueva ley de matrimonio civil (Santiago, 2004), p. 3.473: "La señora Matthei. Señor Presidente, hay ciertos contratos que tienen una forma distinta cuando la persona que los celebra es casada que cuando es soltera, y el tercero -o sea, la contraparte-no tendrá cómo saber si la persona es casada si el contrato se efectúa en esos ocho días entre los que se celebró el matrimonio religioso pero no todavía el civil, ya que, obviamente en el Registro Civil la persona todavía va a aparecer como soltera". 
de 2004, el fiscal nacional del Ministerio Público impartió instrucciones a los fiscales regionales y adjuntos del país, respecto de las modificaciones a los delitos sobre celebración de matrimonios ilegales ${ }^{29}$. En el documento, después de reconocer que la consumación de este delito no precisa la inscripción del acta de matrimonio religioso, se expresa: "por otra parte, si el acta falsificada se logra efectivamente inscribir, ya no estariamos frente a esta nueva figura del artículo 388 del Código penal, sino que derechamente frente a la falsificación de instrumento público [Código Penal, artículos 193 y 194] cometido por el ministro de culto".

No comparto lo señalado por la instrucción. Entre los delitos de falsedad del acta de matrimonio religioso y falsificación de instrumento público, se produce un concurso aparente, que debe ser resuelto por el principio de especialidad en favor del primero. Asimismo, su tipo penal exige expresamente que la falsedad en el acta o el certificado de matrimonio religioso estén "destinados a producir efectos civiles". De modo que el desvalor de este delito abarca la inscripción del acta o certificado religioso, porque esa es la finalidad de los documentos.

3. Impedimento de la inscripción civil del matrimonio religioso (artículo 389 CP.).

El artículo séptimo No 4 de la Ley No 19.947, reemplazó el artículo 389 por el siguiente: "El tercero que impidiere la inscripción, ante un oficial civil, de un matrimonio religioso celebrado ante una entidad autorizada para tal efecto por la Ley de Matrimonio Civil, será castigado con la pena de presidio menor en su grado minimo o multa de seis a diez unidades tributarias mensuales".

La ratio legis del delito, es tutelar la eficacia del aparente sistema de reconocimiento civil de los matrimonios religiosos. La inscripción ante el oficial del registro civil, es indispensable para su validación como inicio del matrimonio civil. Además, dada su naturaleza religiosa, también se protege la libertad de conciencia y la libertad religiosa de los contrayentes que optaron por dicha celebración.

a) El tipo penal. Es un delito de acción, material e instantáneo. El tipo penal objetivo consiste en impedir la inscripción de un matrimonio religioso. Que sólo puede ser de aquéllos celebrados ante una entidad religiosa de derecho público, de lo contrario la conducta no es típica. El modo de comisión del delito no está singularizado por la ley, pero en

${ }^{29}$ Piedrabuena Richard, Guillermo, Modificaciones a los delitos sobre celebración de matrimonios ilegales, efectuados por la Ley $N^{o} 19.947$ [en línea, consulta: 20 enero 2007] <http://www.ministeriopublico.cl/RepositorioMinpu/Archivos/minpu/Otros $\%$ 20delitos\%20y\%20faltas\%20penales $/ 504 \% 202004$.doc>. 
forma análoga al artículo 384 CP., lo habitual será el engaño, la violencia o la intimidación. También es un delito común. El sujeto activo puede ser cualquier persona, aunque según parece de una interpretación sistemática del párrafo 10, debe ser distinta de los contrayentes y del ministro de culto.

El tipo penal subjetivo se reduce a dolo directo. La naturaleza de la acción típica no es compatible con el dolo eventual.

Por último, la pena del delito es alternativa. Se otorga al juez la facultad de aplicar la pena corporal de presidio menor en su grado mínimo o la pena pecuniaria de multa, cuyo monto puede ser de 6 a 10 UTM.

b) El iter criminis. Es un delito de resultado, que se perfecciona cuando se ha impedido la inscripción del matrimonio religioso, por lo cual es procedente la tentativa y la frustración.

\section{CELEBRACIÓN DE MATRIMONIOS CIVILMENTE ILEGALES}

Forman parte de este grupo los siguientes delitos: la bigamia (artículo 383 CP.), la celebración por un funcionario engañado o forzado (artículo 384 CP.), la simulación del matrimonio (artículo 383 CP.) y la autorización o inscripción de matrimonio prohibido (artículo 388 inciso $1^{\circ} \mathrm{CP}$.). Este último delito, ya fue tratado anteriormente.

\section{Delito de bigamia (artículo 382 CP.).}

El artículo 382 CP., que no fue alterado por la Ley No 19.947 de 2004, señala: "El que contrajere matrimonio estando casado válidamente, será castigado con reclusión menor en su grado máximo".

En la esfera civil, estar casado constituye un impedimento dirimente absoluto $^{30}$ que acarrea la nulidad de todo matrimonio celebrado con posterioridad, pero el legislador considera de tal gravedad esta conducta, que además la sanciona penalmente consagrando el delito de bigamia. Dicha denominación, según lo ha reparado la mayoría de los autores, no tiene fundamento en la norma legal pues basta que se trate de un matrimonio posterior, sin importar que sea necesariamente el segundo.

a) El tipo penal objetivo. El tipo de este delito está integrado por los siguientes elementos:

i) Matrimonio válido anterior: es el elemento esencial del tipo penal, porque es el que define la naturaleza antijurídica o ilícita de la acción (contraer matrimonio). De no concurrir esta circunstancia, la acción no

${ }^{30}$ Ley No 19.947, artículo 5: "No podrán contraer matrimonio: 10 Los que se hallaren ligados por vinculo matrimonial no disuelto". 
solo sería un hecho natural, sino también deseable. El matrimonio requerido por el tipo penal, debe cumplir en forma copulativa los siguientes requisitos: ser anterior, válido y no estar disuelto.

Ser anterior: puede haberse celebrado en Chile o en el extranjero. El matrimonio celebrado en el extranjero: sobre la materia rige el principio locus regit actum (artículo 80 inciso $1^{\circ} \mathrm{LMC}$.). En el fondo y en la forma, es válido en Chile el matrimonio contraído con arreglo a las leyes del país en que fue celebrado. Sin embargo, cuando dicho matrimonio es entre chilenos o entre un chileno y un extranjero, hay excepciones respecto al fondo, las que tienen su fundamento en dos consideraciones: el estatuto personal de los chilenos (Código Civil, artículo 15) y el orden público matrimonial chileno (artículo 80 LMC.).

El matrimonio celebrado en Chile: nuestro sistema matrimonial es monista de matrimonio civil obligatorio con inicios diversos. El único matrimonio con efectos civiles es el matrimonio civil, pero los contrayentes pueden alterar el inicio de su forma de celebración. En lugar de celebrar directamente la ceremonia civil ante el oficial del registro civil, pueden celebrar, en forma previa, el rito religioso de su denominación ante el ministro de culto de alguna de las entidades religiosas de derecho público. De todos modos, siempre estará presente la ceremonia civil y sólo desde su celebración el matrimonio adquiere efectos civiles.

Por tanto, hay que descartar de plano la posibilidad de que el matrimonio religioso, por sí mismo, constituya matrimonio previo susceptible de ser tutelado por el delito de bigamia. Cuando el tipo penal se refiere a contraer matrimonio "estando casado válidamente", exige que el matrimonio previo tenga efectos civiles y el matrimonio religioso no los tiene. Aun cuando actualmente el matrimonio religioso puede ser el inicio del matrimonio civil, lo cierto es que la persona sólo estará válidamente casada cuando se verifique éste. De manera que es irrelevante a ojos de la ley penal, que un sujeto contraiga matrimonio religioso con una persona y luego matrimonio civil con otra.

Ser válido: por esta razón siempre será posible alegar su nulidad (LMC. artículo 49). La acción de nulidad no puede interponerse ante el tribunal de garantía u oral en lo penal que conozca el delito de bigamia, sino ante el juzgado de familia competente (Código Orgánico de Tribunales, artículo 173). Además, el procedimiento penal se suspende, hasta que dicha cuestión se resuelva por sentencia firme (Código Procesal Penal, artículo 324).

No estar disuelto: el matrimonio civil termina por la muerte real o presunta de uno de los cónyuges; o por sentencia firme de nulidad o de divorcio (artículo 42 LMC.). Concurriendo cualquiera de los casos citados, ya no existe matrimonio y la celebración de un nuevo matrimonio no es típica. 
ii) La acción típica: es “contraer matrimonio". La bigamia es un delito formal o de mera actividad, porque se consuma con la sola ejecución de la acción típica; es de acción, porque se requiere que el sujeto lleve a cabo una actividad externa; es especial, porque el sujeto activo sólo debe ser una persona casada válidamente con anterioridad; y es instantáneo, porque se consuma en el instante que se contrae el segundo matrimonio.

En relación a este segundo matrimonio, no se requiere que sea válido, de hecho siempre será nulo por la existencia del impedimento dirimente de "vínculo matrimonial no disuelto". Sin embargo, el tipo penal se refiere a él como un matrimonio. Por consiguiente, para la consumación basta que el segundo matrimonio cumpla con los requisitos de existencia ${ }^{31}$.

Corolario de que el matrimonio religioso carezca de efectos civiles en forma autónoma: su celebración no es idónea para satisfacer la acción típica de "contraer matrimonio". Su ejecución sólo es un acto preparatorio ${ }^{32}$, en consecuencia, la conducta del sujeto que "estando casado válidamente" con una persona contrae matrimonio religioso con otra, no es punible ${ }^{33}$.

b) El tipo penal subjetivo. En este delito el dolo consiste en conocer la existencia del vínculo matrimonial precedente, válido y no disuelto, $\mathrm{y}$ a pesar de ello querer contraer un nuevo matrimonio. La acción típica es compatible con el dolo eventual.

c) El iter criminis. El delito de bigamia es de naturaleza instantánea, porque se consuma al momento de celebrar el nuevo matrimonio. Sin embargo, éste es un acto complejo, por tanto es procedente la frustración y la tentativa.

La manifestación, la información, los cursos de preparación y otras diligencias previas a la celebración del matrimonio, son actos preparatorios no punibles. También el matrimonio religioso celebrado ante un ministro de culto de alguna entidad religiosa de derecho publico, según ya fuera señalado al tratar la acción típica.

2. Celebración de matrimonio por funcionario engañado o forzado (artículo 384 CP.).

El artículo $384 \mathrm{CP}$. señala: "[inciso $1^{\circ}$ ] El que por sorpresa o engaño hiciere intervenir al funcionario que debe autorizar su matrimonio sin haber observado las prescripciones que la ley exige para su celebración, aun cuando el

${ }^{31}$ Los requisitos de existencia son: la diferencia de sexo entre los contrayentes, el consentimiento de recibirse mutuamente como marido y mujer, y la presencia de un oficial del Registro Civil.

${ }^{32}$ Etcheberry Orthusteguy, cit. (n. 7), II, p. 53

${ }^{33}$ Politoff, Sergio - Matus, Jean Pierre - Ramírez, María Cecilia, cit. (n. 23), I, p. 385. 
matrimonio sea válido, sufrirá la pena de reclusión menor en su grado minimo. [inciso $2^{\circ}$ ] Si lo hiciere intervenir con violencia o intimidación, la pena será reclusión menor en sus grados medio a máximo".

Igual que su antecesora de 1884, la Ley de matrimonio civil de 2004 no introdujo modificaciones en este artículo porque la versatilidad de su texto no lo ameritaba. En 1872, la comisión redactora del Código Penal ya consideraba la futura promulgación de una Ley de matrimonio civil en nuestro país, por ese motivo eliminó del modelo español varias referencias a la primacía del la jurisdicción eclesiástica sobre el matrimonio ${ }^{34}$. Para individualizar al sujeto pasivo de este delito, el Código Penal español de 1848 empleaba el concepto "párroco", nuestro Código, en cambio, lo reemplazó por "funcionario", que es neutro, en el sentido de estar desprovisto de cualquier referencia a lo religioso. Por tanto, sin mediar ningún cambio legislativo, el delito pudo proteger a los sacerdotes, originalmente competentes para celebrar matrimonios con efectos civiles; y en seguida a los oficiales del registro civil, que a partir de 1884 desarrollan dicha función.

En la actual Ley de matrimonio civil, como consecuencia del reconocimiento civil de los matrimonios religiosos, surge la interrogante sobre la procedencia de este delito en dichas celebraciones, esta vez, incluyendo a los ministros de culto de las entidades religiosas de derecho público en el concepto funcionario. La respuesta debe ser negativa, porque el tipo penal supone la celebración de un matrimonio civil, no religioso. La descripción típica señala que debe "autorizar su matrimonio sin haber observado las prescripciones que la ley exige para su celebración”, y la ley sólo se ocupa de regular la celebración del matrimonio civil.

a) El tipo penal objetivo. Es un delito material, cuyo resultado consiste en provocar que el oficial del registro civil celebre un matrimonio, infringiendo las formalidades que la ley establece para tal efecto. Es indiferente que sea de aquellas que dan o no lugar a la nulidad del matrimonio, porque el tipo penal se aplica "aun cuando el matrimonio sea válido", de manera que la contravención de cualquier formalidad es causa del delito.

La acción típica son los actos dirigidos a obtener el resultado. No es procedente la omisión, pues la modalidad de comisión debe ser alguna de las siguientes:

"Por sorpresa o engaño": según el Diccionario de la Real Academia Espa-

${ }^{34}$ De Rivacoba y Rivacoba, Manuel, Código Penal de la República de Chile y actas de las sesiones de la comisión redactora del código penal chileno (Valparaíso, Edeval, 1974), p. 396. 
nola, sorprender es "conmover, suspender o maravillar con algo imprevisto, raro o incomprensible" 35 y engañar es "inducir a otro a tener por cierto lo que no lo es, valiéndose de palabras o de obras aparentes y fingidas" 36 . Aunque no es imprescindible para efectos de consumar el delito, la hipótesis de que el funcionario sea sorprendido, podría importar, a su vez, negligencia de su parte y ocasionar una eventual responsabilidad penal (artículo 388 inciso $1^{\circ} \mathrm{CP}$.).

"Con violencia o intimidación": se trata del funcionario apremiado en forma física (violencia) o psicológica (intimidación) para que autorice el matrimonio con infracción de alguna formalidad legal. Debido a la mayor gravedad de la acción típica, es una figura calificada del delito y se sanciona con una pena más severa.

Es un delito especial y de propia mano, pues la actuación irregular del oficial civil, puede ser provocada por la actividad de uno de los contrayentes o de ambos actuando concertadamente. Jamás de un tercero. Así lo exige el tipo penal cuando dispone que el sujeto actúe sobre el funcionario que debe autorizar "su matrimonio".

b) El tipo penal subjetivo. Las modalidades de comisión son de tal entidad, que suponen plena conciencia y voluntad del autor, de manera que es impensable el dolo eventual.

c) El iter criminis. El delito se consuma cuando el oficial civil ha celebrado el matrimonio sin haber observado las prescripciones que la ley exige para su celebración. Debido a que la celebración matrimonial es un acto complejo, divisible en etapas, es procedente la tentativa y la frustración.

\section{Simulación de matrimonio (artículo 383 CP.).}

El artículo séptimo No 1 de la Ley No 19.947, sustituyó el artículo 383 $\mathrm{CP}$., que actualmente expresa lo siguiente: "El que engañare a una persona simulando la celebración de matrimonio con ella, sufrirá la pena de reclusión menor en sus grados medio a máximo".

El matrimonio a que se refiere el delito, es el civil, no el religioso. En este caso el tipo penal no es tan claro como en los artículos 382 y 384 CP., pero ya está dicho que los matrimonios religiosos carecen de efectos civiles en forma autónoma, de manera que recurrir al derecho penal violentaría su carácter subsidiario. Sería ilógico que un acto no goce de reconocimiento civil y sin embargo se le conceda tutela penal.

a) El bien jurídico. La simulación se distingue de los restantes delitos

${ }^{35}$ Real Academia Española, cit (n. 26), II, p. 1906.

${ }^{36}$ Ibíd, I, p. 835. 
de su párrafo. No corresponde a un caso de celebración de matrimonio, ni siquiera uno nulo. El supuesto de la descripción típica es solamente la ausencia o apariencia del mismo. Los autores opinan que es una especie de fraude, que no requiere necesariamente de una lesión patrimonial como en las defraudaciones de nuestro Código Penal, pero que podría estar destinado a conseguir otro tipo de ventajas, como por ejemplo, el acceso carnal a la victima.

Aquí el bien jurídico no es la constitución jurídica de la familia, el matrimonio o el estado civil, porque dichos valores de ninguna forma se lesionan o se ponen en peligro con la simulación. Tampoco los tratadistas han conseguido precisar el asunto. En definitiva, coincidiendo con Etcheberry, opino "en caso de que a través de la simulación de matrimonio se logre acceso carnal constitutivo de delito o se produzca estafa, estos últimos títulos consumirán, desplazando, al de simulación de matrimonio, en virtud del principio de la consunción (concurso aparente)"37.

b) El tipo penal. El tipo penal objetivo consiste en la acción de aparentar la celebración de un matrimonio civil con el objeto de engañar al otro contrayente. Es indispensable que el engaño tenga entidad suficiente para producir ese efecto, lo que se determina atendiendo las circunstancias del caso concreto, como la edad, condición social y nivel educacional de la víctima.

El autor puede ser cualquiera de los contrayentes, pero no ambos a la vez. Tampoco puede ser un tercero, de modo que es un delito especial y de propia mano. "Sin embargo, es prácticamente imposible que la simulación de un matrimonio se efectúe sin la intervención de terceras personas, todas las cuales, en caso de actuar con conocimiento de la situación, asumirán la condición de coautores" ${ }^{\prime 8}$. Por los mismos argumentos expresados al tratar la autorización de matrimonio prohibido por el ministro de fe, en mi opinión, la conducta de los colaboradores no es típica.

En el ámbito subjetivo del tipo penal, sólo corresponde el dolo directo.

c) El iter criminis. Es un delito de resultado, se consuma cuando la víctima es engañada como consecuencia de simular un acto matrimonial con ella. Por lo tanto, es procedente la frustración y la tentativa.

\section{EL PROCESO PENAL}

Todos los delitos contemplados en el párrafo sobre la celebración de matrimonios ilegales son de acción penal pública. El procedimiento

\footnotetext{
${ }^{37}$ Etcheberry Orthusteguy, cit. (n. 7), IV, p. 37.

${ }^{38}$ Rodríguez Collao, cit. (n. 10).
} 
puede iniciarse de oficio por el Ministerio Público, o bien por denuncia o querella.

Por regla general, será aplicable el procedimiento ordinario. Aunque podrá aplicarse el procedimiento abreviado (Código Procesal Penal, artículo 406) o simplificado (Código Procesal Penal, artículo 388), según las circunstancias del caso. El primero será aplicable cuando el fiscal pide la aplicación de una pena privativa de libertad no superior a cinco ańos de presidio o reclusión menores en su grado máximo y el imputado acepte los hechos de la acusación y los antecedentes de investigación. El segundo, en cambio, procederá cuando la pena solicitada por el fiscal no supera los 541 días de presidio o reclusión menores en su grado mínimo.

En materia de salidas alternativas, son improcedentes los acuerdos reparatorios (Código Procesal Penal, artículo 241), porque el bien jurídico protegido por estos delitos no es disponible de carácter patrimonial. En cambio es posible la suspensión condicional de procedimiento (Código Procesal Penal, artículo 237), cuando la pena que pudiera imponerse al imputado no supere los tres años de presidio o reclusión menor en su grado medio y el imputado no hubiere sido condenado anteriormente.

\section{CONCLUSIÓN}

La circunstancia de que el matrimonio religioso carezca de efectos civiles en forma autónoma, conduce a que la tipificación de delitos respecto de aquéllos no sea lesiva para ningún bien jurídico y que, en caso de exigirlo el respectivo tipo penal, tampoco sea capaz de provocar perjuicios a terceros. De manera que su aplicación es improcedente, porque se da una presunción de derecho de responsabilidad penal en el primer caso y una tentativa inidónea en el segundo. A pesar de todo, los delitos aludidos son ley vigente y constituyen una amenaza potencial para la libertad de los ministros de culto. Es deseable un cambio legislativo que armonice el ordenamiento jurídico y respete la naturaleza subsidiaria del derecho penal. A la espera de ese improbable evento, este trabajo ha buscado entregar los argumentos jurídicos para minimizar su aplicación.

[Recibido el 14 de diciembre de 2007 y aceptado el 5 de mayo de 2008]

\section{BIBLIOGRAFÍA:}

Biblioteca del Congreso Nacional, Historia de la Ley No 19.947: establece nueva Ley de matrimonio civil (Santiago, 2004).

Cámara de Diputados, Boletín 3732-18, 30 de noviembre de 2004. Modifica Ley 
de Matrimonio Civil para perfeccionar el reconocimiento civil de los matrimonios celebrados ante entidades religiosas.

Cury Urzúa, Enrique, Derecho penal. Parte general (Santiago, Editorial Jurídica de Chile, 1992), II.

Etcheberry orthusteguy, Alfredo, Derecho penal ( $3^{\text {a }}$ edición, Santiago, Editorial Jurídica de Chile, 2004), IV.

De Rivacoba y Rivacoba, Manuel, Código penal de la República de Chile y actas de las sesiones de la comisión redactora del código penal chileno (Valparaíso, Edeval, 1974).

García y García, Antonio, Historia del Derecho canónico (Salamanca, 1967).

Garrido Montt, Mario, Derecho penal (2a ed., Santiago, Editorial Jurídica de Chile, 2005), III.

Pacheco, Joaquín Francisco, El código penal, concordado y comentado (4a edición, Madrid, 1870), III.

Piedrabuena Richard, Guillermo, Modificaciones a los delitos sobre celebración de matrimonios ilegales, efectuados por la Ley $N^{o} 19.947$ [en linea, consulta: 20 enero 2007] <http://www.ministeriopublico.cl/RepositorioMinpu/Archivos/minpu/ Otros\%20delitos\%20y\%20faltas\%20penales/504\%202004.doc>.

Politoff, Sergio - Matus, Jean Pierre - Ramírez, María Cecilia, Lecciones de derecho penal chileno. Parte general (2a edición, Santiago, Editorial Jurídica de Chile, 2003), I.

Rodríguez Collao, Luis, Protección penal del estatuto jurídico del matrimonio, en Guzmán Brito, Alejandro (ed.), Colección de estudios de derecho civil en homenaje a la profesora Inés Pardo de Carvallo (Ediciones Universitarias de Valparaíso, Pontificia Universidad Católica de Valparaíso, Valparaíso, 2008), pp. 181-196.

Salinas Araneda, Carlos, Matrimonio civil y matrimonio religioso, en VV. AA., El nuevo derecho chileno del matrimonio (Santiago, Editorial Jurídica de Chile, 2006.), pp. 49-100. 
